\title{
An Evolutionary Game Study on Participants' Strategies in the Appeal Work of the Express Industry
}

\author{
Chunming Yang ${ }^{1, \mathrm{a}}$, Xueyan Shao ${ }^{2, \mathrm{~b}}$ \\ ${ }^{1}$ School of Engineering Science, University of the Chinese Academy of Sciences, Beijing, China \\ ${ }^{2}$ Institutes of Science and Development, Chinese Academy of Sciences, Beijing, China
}

\begin{abstract}
In response to the outstanding issues such as malicious appeals in the appeal work of China's express industry at this stage, this paper uses the evolutionary game method to study the evolutionary path and equilibrium strategy of the State Post Bureau, the consumers who filed the appeal and the express companies that received the appeal. This study analyzes the interest relationship of each participants in the process of handling appeals, then puts forward countermeasures and suggestions to regulate the appeal work of the express delivery industry from the perspective of the supervisory department.
\end{abstract}

\section{Introduction}

Appeal refers to a citizen, legal person, or other organization who believes that the result of a certain issue is incorrect, he appeals to the relevant state agency for reasons and requests for reprocessing. As an important public affair, appeal work has always been a hot issue of concern to all sectors of society. Robert K. Christensen[1] analyzed sample cases of appeals and judgments in American from 1971 to 1996 and studied various potential reasons that lead to inefficiency. This study takes the appeal supervision of the express industry as an example to analyze the evolutionary game relationship of the behavioral strategies of the participants in the appeal supervision. The evolutionary game method has been widely used in public management $[2,3]$, supply chain management[4], innovation management[5] and other fields. Scholars have also tried to use the evolutionary game method as a tool for government supervision. Mojgan Askarizadeh[6] discussed the evolutionary game model of rumor dissemination, dividing network users into three categories: rumor spreaders, anti-rumor spreaders and rumor neglecters. The rumor control mechanism is considered by the proportion of anti-rumor messages sent by the rumor control center. Reza Mahmoudi[7] used two group evolutionary game theory methods for the first time to simulate the comparison between government goals and producer goals in different situations.

According to article 65 of the "Postal Law of the People's Republic of China", express enterprises shall promptly and properly handle users' objections to service quality. If the user is not satisfied with the processing result, he can appeal to the postal administration department. The postal administration department shall deal with it in a timely manner according to law. However new situations and new problems emerged with the continuous and rapid development of the express industry. Consumers are full of new expectations for better express service experience. There have been malicious appeals and professional complainants accompanied by factors such as the diversification of express companies' operating mechanisms and different internal management levels, which have brought tremendous pressure to the operation of express companies.

The State Post Bureau of the People's Republic of China publishes the "Notice on Consumer Appeals in the Express Industry" to the public every month. As an important means of monitoring appeals, the "Notice" takes consumer satisfaction as the main indicator and contains relevant evaluation result on the appeals of express companies. However, because consumer satisfaction can have a huge impact on the evaluation ranking of a company, some certain consumers will file appeals that exceed the reasonable appeal limit. Such appeals are often difficult to distinguish. Unless the amount of compensation is huge, companies may also provide compensation to such appeals in order to maintain the evaluation ranking. Almost all express companies have relevant records of similar malicious appeals and there are many examples of successful malicious appeals. In these cases, users of malicious appeals have become more unscrupulous due to the lack of judging rules and punitive measures for malicious appeals by the regulatory authorities. From the perspective of the government supervisory department of the express industry, this article discusses the evolutionary game relationship among the three participants including the express industry government supervisory department, the consumers who filed the appeals and the express companies that received the appeals based on the evaluation method.

This study explores the general law of how these three participants evolve from an unhealthy appeal state to a

\footnotetext{
a email: m15510995430@163.com

bemail: xyshao@casisd.cn
} 
healthy appeal state in the process of mutual interest game, analyzes how can the government use appeal costs and malicious appeal penalties to guide the evolution to a benign state. Aiming to improve the management level of the appeal process, we give suggestions on how to give full play to the responsibilities of government supervisory department, promote enterprises to actively improve service quality and guide consumers to protect their rights in accordance with the law.

\section{Model description}

\subsection{Basic Assumptions}

Assume that the subjects involved in the game model of appeal work in the express industry are divided into three players: the State Post Bureau (hereinafter referred to as the government supervisory department), the consumers who filed the appeal (hereinafter referred to as the consumers) and the express companies that received the appeal (hereinafter referred to as the express companies). That is, the players in the game gathered as:

$$
N=\{1,2,3\}
$$

Among them, player 1 represents the government supervisory department, player 2 represents consumers and player 3 represents the express companies.

Assume that three players participating in the game are boundedly rational. And the information is asymmetric and incomplete.

\subsection{Player Strategy Selection and Parameter Setting}

Some indicators such as the appeal handling satisfaction rate that consumers are directly concerned about can be evaluated, so as to give play to the social collaborative supervision effect on express companies. This regulatory strategy is called result evaluation. The evaluation items involved in the appeal process can be included in the indicator system, such as the rate of one-time case closure, to warn express companies that they shall always take improving their own appeal processing level as the ultimate goal. This regulatory strategy is called process evaluation. In this model, the strategy choice space of player 1 is recorded as $\mathrm{X} 1=\{\mathrm{RE}$ (result evaluation), PE(process evaluation) $\}$. The probability that the government supervisory department chooses the result evaluation is $x(0 \leq x \leq 1)$.

After the consumer submits the appeal and cooperates with the handling, he can fill in the appeal handling system whether he is satisfied with the result of the company's appeal handling. This statistic will be reflected in the appraisal results of the express company's appeal work. Consumers can use this as a coercive method to make unreasonable appeals in order to obtain overpayments. That is, the strategy choice space of player 2 is $\mathrm{X} 2=\{\mathrm{OA}$ (overpayment appeal), NA(normal appeal) $\}$. The probability of consumers choosing an overpayment appeal is $\mathrm{y}(0 \leq y \leq 1)$.

According to the appeal handling regulations, companies should compensate consumers when they make normal appeals and make no compensation for overpayment appeals. These two situations are referred as compliance treatment. If the company does not pay compensation when the consumer makes a normal appeal, but pays compensation when the consumer makes an overpayment appeal, these two situations are called noncompliance treatment. Then the strategy choice space of player 3 is $\mathrm{X} 2=\{\mathrm{CT}$ (compliance treatment), $\mathrm{NCT}$ (noncompliance treatment) $\}$. The probability of express companies choosing a compliance treatment is $\mathrm{z}(0 \leq z \leq 1)$.

\subsection{Player's Payoff Matrix}

Government supervisory department: If a company chooses a compliance treatment, the overall service level of the industry will be improved. The improvement of the industry level is regarded as the potential income of the government supervisory department. The degree of this improvement is $G_{1}$. When the government conducts the evaluation of results, since the satisfaction evaluation of consumers can greatly influence the evaluation results of enterprises, enterprises often provide compensation in order to maintain their own evaluation rankings if consumers complain about overpayments, that means overpayment appeals are more likely to succeed. Due to the government's appraisal guidance, consumers' appeals about overpayment will bring negative comments to the government's appraisal work and affect the credibility of the government supervisory department. This kind of loss is $-G_{2}$. The government only needs to accept the statistical data of the system and publish it in the evaluation of the results, without incurring additional costs. However, the production and statistics of various indicators during the evaluation of the process require additional manpower and investment. The management cost is $-G_{3}$.

Consumers: Consumers can get normal compensation $C_{1}$ when they make normal appeals or receive excess compensation $C_{2}$ when they succeed in an overpayment appeal, which is approximately several times the normal compensation. In addition, there is an additional risk of dishonesty when making an appeal for overpayment, which is recorded as $-C_{3}$.

Express companies: If the company does not pay when the government evaluates the results, it will be reflected in the statistics and rankings announced to the society, which will have an impact on the company's subsequent operations and stock prices. This kind of loss is $-E_{1}$, which is much greater than the appeal compensation. If an enterprise refuses to compensate for an overpayment appeal, it will not incur any other direct costs except for $-E_{1}$. If the company makes an excess compensation, it will not be held accountable by the government supervisory department. However, If the company does not make compensation when the consumer only makes a normal appeal, it will be held accountable by the 
government management department and fined. The amount of the fine is $-E_{2}$. And the company needs to make up the normal compensation for consumers after that. In addition, the company will also generate corresponding compensation $C_{1}$ or $C_{2}$ when making compensation.

According to the above conditions, the player's payoff matrix can be obtained as shown in the table:

TABLE 1 Player's Payoff Matrix

\begin{tabular}{|c|c|c|c|c|}
\hline & \multirow[t]{2}{*}{$N_{2}$} & \multicolumn{2}{|l|}{$N_{3}$} \\
\hline & & & $\begin{array}{l}\text { CT } \\
z\end{array}$ & $\begin{array}{l}\mathrm{NCT} \\
1-z\end{array}$ \\
\hline \multirow[t]{4}{*}{$N_{1}$} & \multirow[t]{2}{*}{$\begin{array}{c}\mathrm{RE} \\
x\end{array}$} & $\begin{array}{l}\mathrm{OA} \\
y\end{array}$ & $\left(G_{1}-G_{2},-C_{3},-E_{1}\right.$ & $\left(-G_{2}, C_{2}-C_{3},-C_{2}\right.$ \\
\hline & & $\begin{array}{l}\mathrm{NA} \\
1-y\end{array}$ & $\left(G_{1}, C_{1},-C_{1}\right)$ & $\left(0, C_{1},-E_{1}-E_{2}\right)$ \\
\hline & \multirow[t]{2}{*}{$\begin{array}{l}\mathrm{PE} \\
1-x\end{array}$} & $\begin{array}{l}\mathrm{OA} \\
y\end{array}$ & $\left(G_{1}-G_{3},-C_{3}, 0\right)$ & $\left(-G_{3}, C_{2}-C_{3},-C_{2}\right)$ \\
\hline & & $\begin{array}{l}\text { NA } \\
1-y\end{array}$ & $\left(G_{1}-G_{3}, C_{1},-C_{1}\right)$ & $\left(-G_{3}, C_{1},-E_{2}\right)$ \\
\hline
\end{tabular}

\subsection{Evolutionary Game Model Analysis}

From the table above, the average fitness of the government supervisory department is:

$$
\left\{\begin{array}{c}
U_{x}=z G_{1}-(1-z) y G_{2} \\
U_{1-x}=z G_{1}-G_{3}
\end{array}\right.
$$

The replicated dynamic equation of the probability that the government supervisory department chooses the "result evaluation" strategy is:

$$
F(x)=\frac{d x}{d t}=x\left(U_{x}-\bar{U}\right)=x(1-x)\left[(z-1) y G_{2}+G_{3}\right]
$$

According to the stability theorem of differential equations, only when $F(x)=0$ and $F^{\prime}(x)<0$, the probability of the government supervisory department choosing the result evaluation strategy can be in a stable stage.

Proposition 1. When $z>z_{0}$, the stabilization strategy of the government supervisory department is to conduct result evaluation. When $z<z_{0}$, its stabilization strategy is to conduct process evaluation. When $z=z_{0}$, the stabilization strategy cannot be determined. The threshold:

$$
z_{0}=1-\frac{G_{3}}{y G_{2}}
$$

The partial derivative with respect to $x$ of $F(x)=0$ can be obtained:

$$
\frac{\partial F(x)}{\partial x}=(1-2 x)\left[(z-1) y G_{2}+G_{3}\right]
$$

Proof. Let $H(z)=(z-1) y G_{2}+G_{3}, \quad \partial H(z) / \partial z$, so $H(z)$ is an monotone increasing function of $z$. Let $H\left(z_{0}\right)=0$, then $z_{0}=1-\frac{G_{3}}{y G_{2}}$. If $z>z_{0}, H(z)>0$,
$\left.F(x)\right|_{x=1}=0$ and $\left.F^{\prime}(x)\right|_{x=1}<0, \quad x=1 \quad$ is evolutionary stability strategy. If $z<z_{0}, \quad H(z)<0,\left.\quad F(x)\right|_{x=0}=0$ and $\left.F^{\prime}(x)\right|_{x=0}<0, \quad x=0$ is evolutionary stability strategy. If $z=z_{0} \quad, \quad F(x)=0$ and $F^{\prime}(x)=0$, government supervisory department cannot determine evolutionary stability strategies.

Proposition 1 shows that the increase in the probability of express companies choosing non-compliance treatment will make the government supervisory department's stabilization strategy change from result evaluation to process evaluation. Therefore, the performance and feedback of enterprises in handling appeals will directly affect the evaluation methods adopted by government supervisory department.

In the same way, it can be proved that the increase in the probability of consumers choosing overpayment appeals will shift the stability strategy of the government supervisory department from result evaluation to process evaluation. This shows that government supervisory department will tend to adopt process evaluation if consumers tend to choose overpayment appeals, in order to avoid companies being restricted and make noncompliance treatment, which affects the quality of the express industry appeal work. If consumers tend to choose normal appeals, for cost considerations, government supervisory department will tend to use result evaluation.

According to Proposition 1, the phase diagram of the government supervisory department's strategy selection is obtained, as shown in the figure:

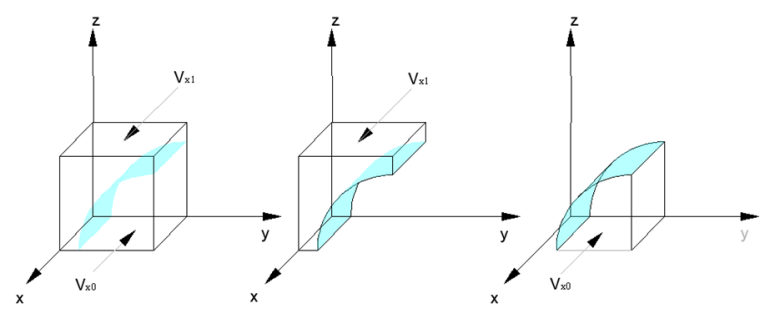

Figure 1 The phase diagram of the strategy selection of the government supervisory department

In Fig. 1, the volume of part $V_{x 1}$ is the probability that the government supervisory department adopts the result evaluation and the volume of part $V_{x 0}$ is the probability that the government supervisory department adopts the process evaluation. Calculate the volume:

$$
\begin{gathered}
V_{x 0}=\int_{0}^{1} \int_{0}^{1} z_{0} d x d y=\frac{G_{2}-G_{3}}{G_{2}}+\frac{G_{3}}{G_{2}} \ln \frac{G_{3}}{G_{2}} \\
V_{x 1}=1-V_{x 0}=\frac{G_{3}}{G_{2}}-\frac{G_{3}}{G_{2}} \ln \frac{G_{3}}{G_{2}}
\end{gathered}
$$

Proposition 2. The government supervisory department is more inclined to conduct process evaluation when the loss caused by enterprise feedback increases. The government department tends to conduct result evaluation when the management cost increases.

Proof. Let $k=\frac{G_{3}}{G_{2}} \in(0,1)$, then $V_{x 1}=k-k \ln k$, $d V_{x 1} / d k=-\ln k>0$, so $V_{x 1}$ is an monotone increasing 
function of $k$. Thus, $V_{x 1}$ is an monotone decreasing function of $G_{2}$ and an monotone increasing function of $G_{3}$.

Using the above analysis method, we can establish replicated dynamic equations for consumers and express companies respectively and analyze the partial derivatives. Here is a copy of the dynamic equations and phase diagrams.

$$
F(y)=y(1-y)\left[-C_{1}+(1-z) C_{2}-C_{3}\right]
$$

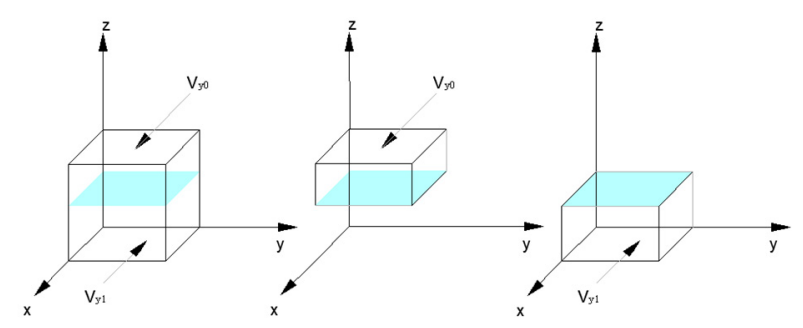

$F(z)=z(1-z)\left[-(1-y) C_{1}+y C_{2}+(1-2 y) x E_{1}+(1-y) E_{2}\right](9)$

Figure 2 The phase diagram of the strategy selection of

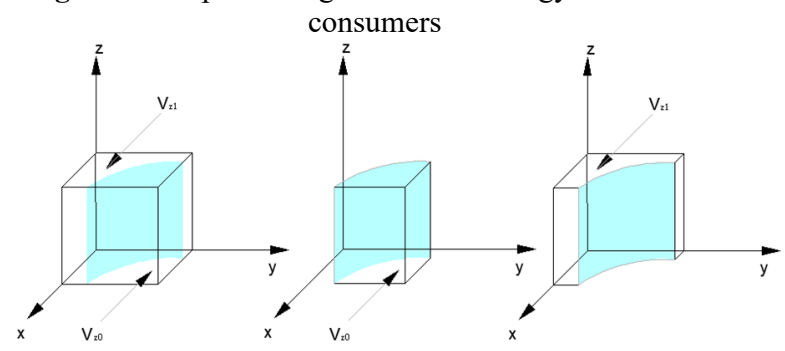

Figure 3 The phase diagram of the strategy selection of express companies

The derivation process will not be repeated here. The results of the derivation are shown as follows:

The increase in the probability that express companies choose to deal with non-compliance treatment will cause consumers' stabilization strategy to shift from normal appeals to overpayment appeals. Similarly, the increase in the probability of express companies' choice of compliance treatment will make consumers' stabilization strategies change from the overpayment appeal to a normal appeal. Therefore, companies choose to deal with non-compliance is an important reason that encourages consumers to appeal for overpayment. Besides, consumers are more inclined to make an overpayment appeal when the amount of compensation that may be obtained for an overpayment appeal increases, while tend to make a normal appeal when the risk of dishonesty increases.

The increase in the probability of consumers choosing overpayment appeal will cause the express company's stabilization strategy to change from compliance treatment to non-compliance treatment. Similarly, the increase in the probability of consumers choosing normal appeal will cause the express company's stabilization strategy to change from non-compliance treatment to compliance treatment. Besides, the express companies are more inclined to deal with non-compliance when the turnover and stock price losses caused by the evaluation ranking increase. On the contrary, they tend to deal with the compliance when this loss is reduced.

\section{Conclusions}

From the perspective of the government supervision department, we study the supervision of the express industry appeal work. This paper constructs an evolutionary game model of the appeal work involving the government supervision department, consumers and express companies. The stability of each player's strategy choice is analyzed, which is helpful to clarify the influencing factors of each party's decision and discuss the appropriate evaluation method in the follow-up. The main conclusions are as follows:

Government supervisory department tends to conduct result evaluation when consumers make normal appeals and express companies take compliance treatment. This is an ideal situation. Government supervisory department tends to conduct process evaluation when consumers appeal for overpayment and express companies take noncompliance treatment. This situation is not conducive to the reasonable and orderly handling of appeals.

The cost of untrustworthiness for consumers to appeal is the key to solving the problem of malicious appeals. Only if there is sufficient untrustworthiness cost can the express appeal work be on the right track. The decisions of consumers and express companies will affect the evaluation methods of government supervisory department. In the absence of complete rules and regulations, the process evaluation model with higher regulatory intensity can be an effective alternative. However, due to the constraints of regulatory costs, it cannot be a long-term solution. The fundamental solution should still start from formulating effective regulations, trying to increase the risk of untrustworthiness of overpayment appeals.

\section{Acknowledgment}

We thank the relevant departments of the express industry for their cooperation in the research activities of this paper. We also thank our colleagues at the University of Chinese Academy of Sciences, especially Guowei Jia. Their valuable suggestions have greatly improved the quality of the manuscript.

\section{References}

1. R. K. Christensen and J. Szmer(2012) Examining the efficiency of the U.S. courts of appeals: Pathologies and prescriptions. International Review of Law and Economics, vol. 32, no. 1, pp. 30-37.

2. A. Antoci, S. Borghesi, M. Galeotti.(2013) Environmental options and technological innovation: an evolutionary game model. Journal of Evolutionary Economics, vol. 23, no. 2.

3. Z. Feng, L. Yang, J. Liu, M. Zhou, W. Zhang, and K. Wang.(2017) Evolutionary game analysis of the illegal occupancy behavior of the motorway emergency lane. Cognition, Technology \& Work, vol. 19, no. 2-3.

4. Z. LIU and T. NISHI.(2020) Analyzing just-in-time 
purchasing strategy in supply chains using an evolutionary game approach. Journal of Advanced Mechanical Design, Systems, and Manufacturing, vol. 14 , no. 5 .

5. E. Ozkan-Canbolat, A. Beraha, and A. Bas.(2016) Application of Evolutionary Game Theory to Strategic Innovation. Procedia - Social and Behavioral Sciences, vol. 235.

6. M. Askarizadeh, B. T. Ladani, and M. H. Manshaei.(2019) An evolutionary game model for analysis of rumor propagation and control in social networks. Physica a-Statistical Mechanics and Its Applications, vol. 523, pp. 21-39.

7. R. Mahmoudi and M. Rasti-Barzoki(2018) Sustainable supply chains under government intervention with a real-world casecase study: An evolutionary game theoretic approach. Computers \& Industrial Engineering, vol. 116, pp. 130-143. 